\section{S.Ziyeh \\ A.Berlis \\ U.H.Ross \\ M. J. Reinhardt \\ M. Schumacher}

\title{
MRI of active otosclerosis
}

\begin{abstract}
Our aim was to determine whether MRI reliably shows pathology in patients with active otosclerosis (otospongiosis). We studied five patients with clinical and audiometric signs of this disorder and positive findings on high-resolution CT and tympanocochlear scintigraphy. Contrast enhancement of otospongiotic lesions was found in all affected ears, and could be topographically related to demineralised otospongiotic foci on CT. In lesions in the lateral wall of the labyrinth MRI sometimes showed the pathology better than CT, where partial-volume effects could be troublesome.
\end{abstract}

Key words Otosclerosis, otospongiosis $\cdot$ Computed tomography $\cdot$ Magnetic resonance imaging $\cdot$ Tympanocochlear scintigraphy
S.Ziyeh $(\bullet) \cdot A$. Berlis $\bullet$ M. Schumacher Section of Neuroradiology, Germany

\section{U.H. Ross}

Department of Otolaryngology, Universitätsklinik, Freiburg, Germany

M. J. Reinhardt

Department of Nuclear Medicine, Universitätsklinik, Freiburg, Germany otosclerosis, due to the poor demonstration of the bone [12]. However, few cases of MRI in otosclerosis have been published $[1,11,13,14]$.

We evaluated MRI as a method for detecting lesions in patients with active otosclerosis, showing typical demineralised lesions in CT and elevated activity on tympanocochlear scintigraphy (TCS).

\section{Patients and methods}

We examined 5 of a group of 29 patients with clinically and audiometrically suspected otosclerosis who fulfilled two additional criteria: demonstration of mineralization defects suggestive of otosclerosis on 2-mm axial and modified coronal CT and activity of the lesions on TCS with 740-800 MB, 99mTc-diphosphono-propanedicarboxylate (Table 1). MRI was performed on a $1 \mathrm{~T}$. Imager, with coronal T2-weighted turbo spin-echo sequences covering the temporal bone (TR 4500, TE $120 \mathrm{~ms}, 2$ acquisitions, $390 \times 512$ matrix and $3 \mathrm{~mm}$ slice thickness). T1-weighted spin-echo images were acquired in the coronal plane and following $0.1 \mathrm{mmol}$ gadolinium

sidered inadequate by some workers for diagnosis of 
Table 1 Clinical and imaging data

\begin{tabular}{|c|c|c|c|c|}
\hline $\begin{array}{l}\text { Patient/sex/ } \\
\text { age (years) }\end{array}$ & Symptoms & $\mathrm{CT}$ & Scintigraphy & MRI \\
\hline $1 / \mathrm{m} / 17$ & $\begin{array}{l}\text { Rapidly progressive } \\
\text { bilateral combined } \\
\text { hearing loss for } 2 \text { years }\end{array}$ & $\begin{array}{l}\text { Bilateral very prominent } \\
\text { otospongiotic lesions adja- } \\
\text { cent to basal, middle and } \\
\text { apical turns of cochlea, } \\
\text { round and oval windows, } \\
\text { facial nerve canal and centre } \\
\text { of lateral semicircular canal }\end{array}$ & $\begin{array}{l}\text { Bilateral marked } \\
\text { activity in bony } \\
\text { labyrinth }\end{array}$ & $\begin{array}{l}\text { T2-weighted: inconspicuous small } \\
\text { pericochlear high signal foci. T1- } \\
\text { weighted: soft tissue signal in perico- } \\
\text { chlear enchondral layer; prominent } \\
\text { endochondral enhancement outlining } \\
\text { the cochlea, and around oval and } \\
\text { round windows in both ears }\end{array}$ \\
\hline $2 / \mathrm{m} / 34$ & $\begin{array}{l}\text { Bilateral combined } \\
\text { hearing loss for } 18 \text { years }\end{array}$ & $\begin{array}{l}\text { Bilateral otospongiotic } \\
\text { lesions adjacent to basal, } \\
\text { middle and apical turns of } \\
\text { cochlea and round and } \\
\text { oval windows }\end{array}$ & Bilateral activity & $\begin{array}{l}\text { T2-weighted: normal T1-weighted: } \\
\text { small foci of soft tissue signal; enhanc- } \\
\text { ing pericochlear foci, around oval and } \\
\text { round windows in both ears }\end{array}$ \\
\hline $3 / f / 46$ & $\begin{array}{l}\text { Bilateral combined } \\
\text { hearing loss for } 20 \text { years }\end{array}$ & $\begin{array}{l}\text { Bilateral otospongiotic le- } \\
\text { sions around basal, middle } \\
\text { and apical turns of cochea, } \\
\text { round and oval windows }\end{array}$ & Bilateral activity & $\begin{array}{l}\text { T2-weighted: normal T1-weighted: } \\
\text { small foci of soft tissue signal; foci of } \\
\text { faint pericochlear enhancement; } \\
\text { prominent enhancement in lateral } \\
\text { wall of vestibule, round and oval win- } \\
\text { dow region bilaterally }\end{array}$ \\
\hline $4 / f / 47$ & $\begin{array}{l}\text { Bilateral severe combined } \\
\text { hearing loss for } 8 \text { years }\end{array}$ & $\begin{array}{l}\text { Bilateral otospongiotic le- } \\
\text { sions adjacent to the basal } \\
\text { turn of cochlea, less con- } \\
\text { spicuous on left }\end{array}$ & Activity on the right & $\begin{array}{l}\text { T1- and T2-weighted: high signal foci } \\
\text { adjacent to basal turn cochlea more } \\
\text { pronounced on the right; marked bi- } \\
\text { lateral contrast enhancement of peri- } \\
\text { cochlear lesions }\end{array}$ \\
\hline $5 / f / 40$ & $\begin{array}{l}\text { Left conductive hearing } \\
\text { loss, stapedotomy } 3 \text { months } \\
\text { previously, postoperatively } \\
\text { progressive hearing loss }\end{array}$ & $\begin{array}{l}\text { Stapes prosthesis; } \\
\text { thickened footplate of } \\
\text { stapes }\end{array}$ & Activity on the left & $\begin{array}{l}\text { T1- and T2-weighted: normal; small } \\
\text { enhancing focus in left oval window } \\
\text { niche }\end{array}$ \\
\hline
\end{tabular}

DTPA $/ \mathrm{kg}$ body weight in coronal and axial planes (TR 550-600, TE $15-17 \mathrm{~ms}, 3-4$ acquisitions, $256 \times 256$ or $192 \times 256$ matrix and $3 \mathrm{~mm}$ slice thickness). The coronal images were obtained in a modified clivus-parallel plane, as used for CT.

Results

In patients 1-4 with retrofenestral otospongiosis T1weighted images revealed foci of soft-tissue signal in the pericochlear lesions, visible in CT (Figs. 1-3). Small inconspicuous high-signal areas could be demonstrated at the same sites on T2-weighted images in patients 1 and 4. Contrast enhacement was seen in all ears positive on CT and TCS. Patients 1-3 had retrofenestral and fenestral otosclerosis and contrast-enhancing lesions could be demonstrated in the pericochlear otic capsule (Figs. 1-3) and the lateral wall of the labyrinth, i.e. the round and oval window region, the cochlear promontory and the tympanic segment of the facial nerve canal (Fig.3). Patient 4 had retrofenestral otospongiotic lesions without fenestral involvement on TCS, CT or MRI. She showed bilateral contrast-enhancing otospongiotic lesions adjacent to the basal and middle turns of the cochlea, in agreement with the results of CT; TCS showed activity on the right side only.
In patients with retrofenestral otospongiotic lesions the degree of contrast enhancement was variable. In patient 1 , with a 2 -year course of rapidly progressive hearing impairment, the entire pericochlear region enhanced strongly and homogeneously (Fig.1). In patients 2 and 3 with chronic otosclerosis, of 18 and 20 years duration, there was less prominent, partial enhancement of the demineralised otospongiotic lesions seen on CT (Figs. 2, 3).

Patient 5 had unilateral fenestral otosclerosis on the left. Stapedotomy and insertion of a prosthesis into the footplate had been performed 3 months previously. However, the patient deteriorated audiometrically postoperatively. On CT the residual left stapedial footplate was thickened and of lower density than in the contralateral ear. There was isolated enhancement in the oval window region on the left.

Contrast enhancement could be topographically related to lesions visible on CT in all ears. Moreover some lesions, not easily distinguished from partial volume artefacts on CT, were better identified on contrast-enhanced MRI. They were otospongiotic foci in the lateral wall of the labyrinth and adjacent to the vestibule. 

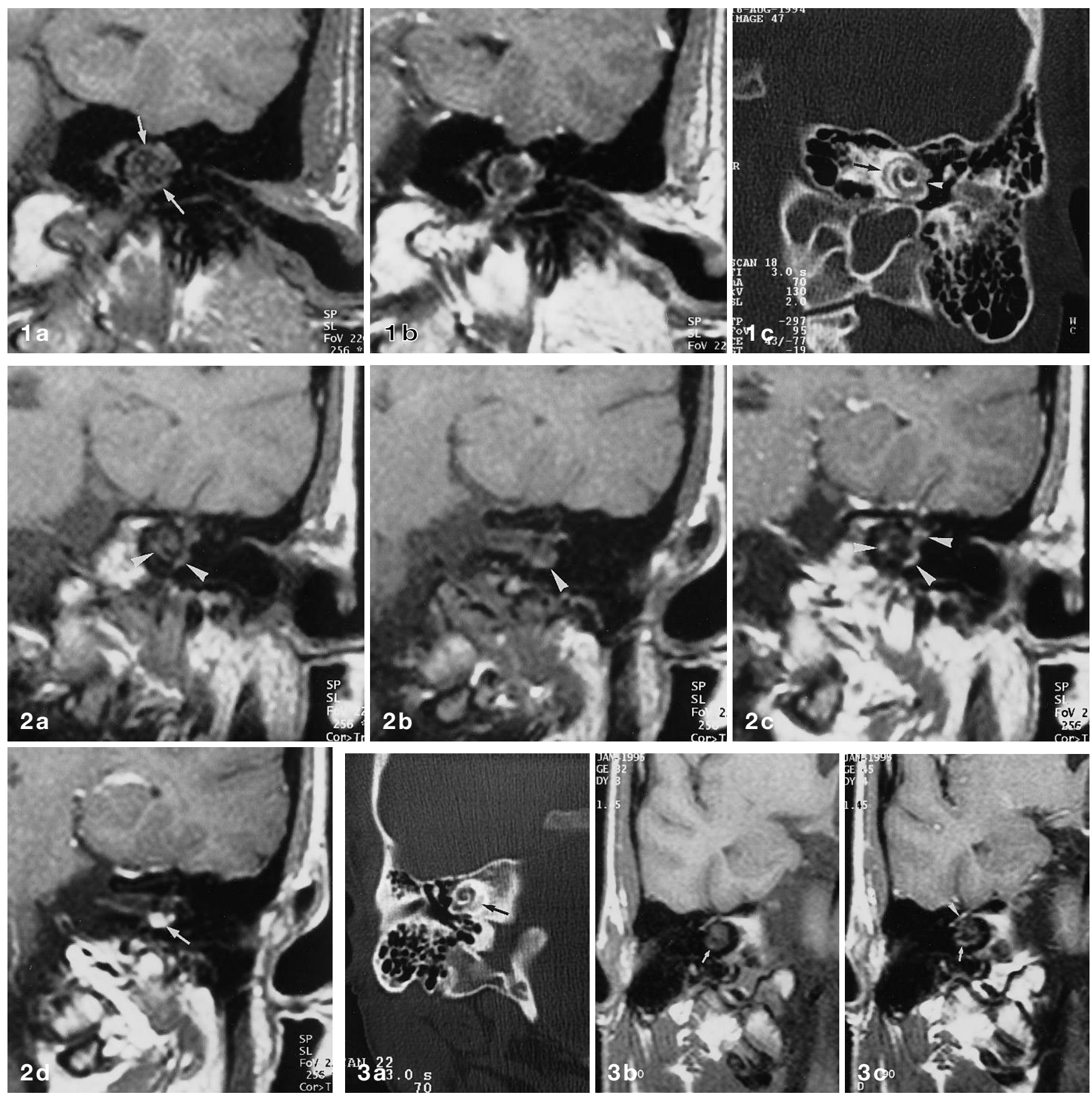

Fig. 1 a $\pm \mathbf{c}$ Patient 1, left ear. Coronal T1-weighted MRI a before, $\mathbf{b}$ after contrast medium, and CT $\mathbf{c}$. Soft-tissue signal in the pericochlear bony labyrinth in a (arrows). b Prominent, complete enhancement of the lesions. c Classical double ring sign with demineralised zone around the basal turn of the cochlea (arrow) at the level of the anterior margin of the oval window (arrowhead)

Fig. 2 a \pm d Patient 3, left ear. T1-weighted images a,c through basal turn of cochlea, $\mathbf{b}, \mathbf{d}$ through vestibule; $\mathbf{c}, \mathbf{d}$ with contrast enhancement. Small soft tissue-signal foci in $\mathbf{a}$ and $\mathbf{b}$ (arrow-

heads). c Enhancement of the anterior margin of the oval window and segmental enhancement of pericochlear lesions (arrowheads). d Prominent enhancement of a perivestibular lesion (arrow)

Fig. 3 a $\pm \mathbf{c}$ Patient 2, right ear. a CT, b,c T1-weighted images before and after contrast medium. a Small low-density otospongiotic foci abut the basal and middle turns of the cochlea (arrow). b Minimal high signal adjacent to the basal turn of the cochlea (arrow). c Segmental enhancement of pericochlear lesions (arrow), and tympanic segment of the facial nerve (arrowhead) 
Discussion

In the resorptive, active phase of osteosclerosis lesions contain a vascular stroma, numerous osteoblasts and osteocytes [15]. In 1900 Siebenmann [16] introduced the term otospongiosis to describe the spongy histological appearance of the affected bone. In a later phase diminution of cellularity, obliteration of blood vessels, remineralisation and formation of lamellar bone take place within the lesion [15]. Histologically, all stages of the process may be present in an affected bone [17].

In fenestral otosclerosis patients may experience progressive conductive hearing loss due to involvement of the margins of the oval window and the footplate of the stapes, causing stapedial dysfunction. In the retrofenestral or cochlear type, sensorineural hearing loss usually evolves in association with conductive hearing loss and sometimes also with vestibular symptoms. The clinical diagnosis is based on the history of usually bilateral and often asymmetrical hearing loss, audiometry, otoscopy and, in two thirds of the patients, a positive family history of hearing disorder [4]. In most patients with fenestral otosclerosis and conductive hearing loss radiology is not necessary. However, some patients may require imaging to confirm the diagnosis of cochlear otosclerosis [14] or to exclude a retrocochlear lesion such as a coexisting acoustic schwannoma [18].

In the first half of the 1980s high resolution CT was suggested for patients with otosclerosis [6-10]. It can be used to show the extent of the pathology of the oval window and the footplate of the stapes, and when the diagnosis of otosclerosis is in doubt. It may also be used to show capsular involvement in cases with combined hearing loss [11]. In the fenestral type CT may demonstrate widening of the oval window, thickening of the footplate of the stapes and small low-density lesions in the lateral wall of the labyrinth [8]. CT can show cochlear involvement in the retrofenestral type, where the so-called double ring sign is typical, a low-density demineralised enchondral defect outlining the cochlea [7]. In the sclerotic phase the lesions may undergo remineralisation and become indistinguishable from the normal otic capsule on CT [1,7].

TCS [19] shows high activity at the site of otospongiotic bone resorption due to its affinity for immature, highly hydrated hydroxyapatite. It reveals activity of the process but anatomical landmarks are less clearly shown than on CT or MRI.

Our results indicate that MRI represents an additional imaging method with a high potential for demonstrating active otosclerotic lesions. The most reproducible finding - present in all cases of active otosclerosis was contrast enhancement of otospongiotic lesions. We presume that this is due to contrast medium pooling in the numerous blood vessels of the otospongiotic foci.
Our observations suggest a positive correlation between intensity of the contrast enhancement and activity of the process [11] but more data are needed. A longitudinal study could be used to evaluate this method for monitoring therapeutic, especially pharmacotherapeutic, studies in otospongiosis.

The results of TCS and contrast-enhanced MRI were congruent except in patient 4 , in whom we presume that positive findings on the left only on MRI indicate a stage in the evolution of an otosclerotic lesion with cesation of bone resorption but with vascular stroma still present and visible on MRI.

The fact that patients 1-3 also showed contrast enhancement in the lateral wall of the labyrinth (Fig.2) confirms that cochlear otosclerosis rarely occurs without fenestral involvement; contrast enhancement was demonstrated in the round and oval window region, cochlear promontory and tympanic segment of the facial nerve canal.

We interpreted the findings in patient 5 as a manifestation of recurrent or residual fenestral otospongiosis, but the differential diagnosis of postsurgical changes has also to be considered.

Our observations in patients with retrofenestral and fenestral otospongiosis indicate that MRI is of diagnostic value in these lesions; this has not been described in previous reports $[1,11,13,14]$.

The geniculate ganglion and the tympanic segment of the facial nerve (Fig. 3), moderately enhancing normal structures [20], may be a source of possible false-positive results. The modified coronal clivus-parallel slice orientation we employed for CT and MRI projects the geniculate ganglion lateral to the superior margin of the basal turn of the cochlea. This segment of the facial nerve typically appears T-shaped in the coronal plane, due to its giving of the greater petrosal nerve. Differentiation between normal enhancement of the tympanic segment and pathological enhancement of the bony facial nerve canal may be difficult or even impossible.

T1-weighted images showed soft-tissue signal in the pericochlear otospongiotic lesions of patients $1-4$. With confluent lesions the cochlea may appear entirely thickened, with an irregular shape (Fig.1). T1-weighted images without contrast medium generally showed the pathology less clearly than contrast-enhanced images in active otosclerosis. They are, however, indispensable for differentiating enhancement from fat-containing bone marrow in the temporal bone.

Showing abnormal signal only in two of five patients, T2-weighted sequences appear relatively insensitive to otospongiotic lesions. However, we found them useful. The fluid of the inner ear gives high signal, and, provided that T2- and contrast-enhanced T1-weighted images are acquired in the same plane, determination of the exact site of an enhancing active otosclerotic lesion is facilitated. 
1. Swartz JD, Harnsberger HR (1992) Imaging of the temporal bone, 2nd edn. Thieme, Stuttgart, pp 227-246

2. Linthicum FH (1993) Histopathology of otosclerosis. Otolaryngol Clin North Am 26: 335-352

3. Barr MS, Lewin JS (1993) Computed tomographic evaluation of otosclerosis. Am J Otolaryngol 14: 282-284

4. Emmett JR (1993) Physical examination and clinical evaluation of the patient with otosclerosis. Otolaryngol Clin North Am 26: 353-357

5. Hannley MT (1993) Audiologic characteristics of the patient with otosclerosis. Otolaryngol Clin North Am 26: 373 387

6. De Groot JA, Huizing EH, Damsma H, Zonneveld FW, Van Waes PF (1985) Labyrinthine otosclerosis studied with a new computed tomography technique. Ann Otol Rhinol Laryngol 94: 223-225
7. Maffee MF, Valvassori GE, Deitch RL, Norouzi P, Henrikcson GC, Capek V, Applebaum EL (1985) Use of CT in the evaluation of cochlear otosclerosis. Radiology 156: 703-708

8. Maffee MF, Henrikson GC, Deitch RL, Norouzi P, Kumar A, Kriz R, Valvassori GE (1985) Use of CT in stapedial otosclerosis. Radiology 156: 709-714

9. Swartz JD, Faerber EN, Wolfson RJ (1984) Fenestral otosclerosis: significance of preoperative CT evaluation. Radiology 151: 703-707

10. Swartz JD, Mandell DW, Berman SE (1985) Cochlear otosclerosis (otospongiosis): CT analysis with audiometric correlation. Radiology 155: 147-150

11. Valvassori GE (1993) Imaging of otosclerosis. Otolaryngol Clin North Am 26: 359-371

12. Helms J (1994) Otosklerose. In: Helms J (ed) Oto-Rhino-Laryngologie in Klinik und Praxis, vol 1. Thieme, Stuttgart, pp 726-741

13. Mark AS, Seltzer S, Harnsberger HR (1993) Sensorineural hearing loss: more than meets the eye? AJNR 14: 37-45

14. Saunders JE, Derebery MJ, Lo WW (1995) Magnetic resonance imaging of cochlear otosclerosis. Ann Otol Rhinol Laryngol 104: 826-829
15. Davis GL (1987) Pathology of otosclerosis. Am J Otolaryngol 8: 273-281

16. Siebenmann (1900) Ueber einen weiteren Fall von Spongiosirung der Labyrinthkapsel, mit dem klinischen Bilde der Stapesankylose beginnend und mit completer Taubheit endigend, in Folge Hinzutretens von Neuritis interstitialis acustica. Monatsschr Ohrenheilkd 34: 28-29

17. Guild SR (1944) Histologic otosclerosis. Ann Otorhinolaryngol 53: 246-266

18. Clemis JD, Toriumi DM, Gavron JP (1988) Otosclerosis masking coexistent acoustic neuroma. Am J Otol 9: 117121

19. Bornemann H, Hundshagen H, Franke KD (1981) Digitale Szintigraphie des Ohres. Arch Ohren Nasen Kehlkopfheilkd 231: 689-691

20. Sartoretti-Schefer S, Wichmann W, Valavanis A (1994) Idiopathic, herpetic, and HIV-associated facial nerve palsies: abnormal MR enhancement patterns. AJNR 15: 479-485 